\title{
Axons Added to the Regenerated Visual Pathway of Goldfish Establish a Normal Fiber Topography Along the Age-Axis
}

\author{
ROBERT BERNHARDT, STEPHEN S. EASTER, JR., AND PAMELA A. RAYMOND \\ Departments of Biology (R.B., S.S.E.) and of Anatomy and Cell Biology, Medical School
} (P.A.R.), The University of Michigan, Ann Arbor, Michigan 48109-1048

\begin{abstract}
Throughout a goldfish's life, new generations of ganglion cells are added on the retinal margin and their axons extend centrally to occupy predictable positions in the retinotectal pathway, adjacent to their predecessors and subjacent to the pia. The stacking of successive generations of axons defines the age-axis of the pathway. This study examined whether an ordered array of predecessor axons is a prerequisite for the patterned growth of new axons. One optic nerve was crushed intraorbitally and the fish was injected with $3 \mathrm{H}$-thymidine to label the proliferating cells on the retinal margin. The ring of 3H-thymidine-labeled cells separated retina that was present at the time of nerve crush (inside the ring) from new retina added afterward (outside). After a period of 14-16 months postcrush, both tectal lobes received two punctate applications of horseradish peroxidase (HRP), one in the central and the other in peripheral tectum, to retrogradely label contralateral retinal ganglion cell bodies and their axons.

The pattern of HRP labeling from the control tectum confirmed earlier work: axons on the central tectum had somata in the central retina, and axons on the peripheral tectum had somata in the peripheral retina. The labeled cells and axons were both in predictable patterns. The somata that were backfilled from applications to the center of the experimental tectum lay inside the radioactive ring and had therefore regenerated their axons. The patterns of their labeled axons in the optic pathway and of their somata in the retina were typical of the regenerated condition as described in earlier studies. The somata backfilled from the periphery of the experimental tectum were outside the radioactive ring and had been added after the optic nerve crush. The patterns of their labeled axons and somata were comparable to the normal pattern. These observations indicate that new axons do not depend on an ordered array of predecessors to reestablish normal order along the age-axis of the pathway.
\end{abstract}

Key words: optic nerve, optic tract, axonal outgrowth, axonal guidance

Ordinarily, the cross section of the retinotectal pathway of goldfish is ordered such that axons from old ganglion cells near the optic disk lie at one side of the cross section, and young axons from the peripheral retina lie on the other, thus defining the age-axis of the pathway (Scholes, '79; Easter et al., '81; Bunt, '82; Springer and Mednick, '85, '86; Bernhardt and Easter, '86; Fraley and Sharma, '86). The position of a ganglion cell soma can be described by its distance from the optic disk-its " $r$ " value. The magnitude of $r$ is inversely related to the age of the ganglion cell. Axons are also ordered according to sectoral origin (i.e., the clock face position, $\theta$, of the parent somata). This order defines the $\theta$-axis, which extends perpendicular to the $r$-axis (Scholes, '79; Easter et al., '81; Bunt, '82; Springer and Mednick, '85, '86; Bernhardt and Easter, '86; Fraley and Sharma, '86). In the preceding paper (Bernhardt and Easter, '88) it was shown that the order along the r-axis of the regenerated pathway was very much degraded relative to normal. This paper examines the disposition of axons added

Accepted June 8, 1988. 
after regeneration was complete. We ask the question, "To what extent can these new axons reestablish order along the age-axis after it has been degraded during regeneration?"

It has been suggested that order along the r-axis was built up by successive generations of axons following their predecessors from nearby retinal sites, both during embryogenesis (Bodick and Levinthal, '80) and during regeneration (Stuermer, '86). There is no doubt that during normal development successive generations do exactly that; the question is whether or not their predecessors guided them. The alternative is that other factors lead the axons into their particular trajectories, and the young ones simply follow the same guidance cues as their predecessors, and therefore only seem to track their predecessors.

This paper examines that question. We have taken advantage of the fact that the goldfish retina continues to add new ganglion cells throughout the animal's life (Johns, '77; Meyer, '78). If new axons are added to a regenerated pathway, then this setting should permit an evaluation of the importance of specific axon tracking. Do the new axons follow their neighbors' axons, now randomly dispersed throughout the cross section of the pathway? Or do they course along the same superficial channel that they would have followed if the nerve had never been interruptedthat is to say, superficially, just deep to the pial boundary?

We have addressed this question by crushing the optic nerves of goldfish and then allowing them more than a year to 1) regenerate the severed axons and 2) add new ones (at the rate of 40-50 per day; Easter et al., '81). Selected groups of regenerated and of newly added axons and cell bodies were then labeled with horseradish peroxidase (HRP), and the retinae and optic pathways were incubated to show the locations of the somata and their axons. We conclude that new axons coursed in the normal location, despite the fact that their regenerated predecessors were elc shere. Thus, the new axons did not need an orderly array of predecessors to recapture their proper positions in the pathway. This indicates that new axons do not specifically track their slightly more central neighbors. Order along the r-axis of the pathway is apparently established on the basis of other cues.

An abstract of this work has been presented previously (Bernhardt et al., '86).

\section{MATERIALS AND METHODS}

\section{Optic nerve crush and $3 \mathrm{H}$-thymidine labeling}

Small goldfish (25-35-mm standard body length) were anesthetized with $0.1 \%$ tricaine methanesulfonate (Sigma). The right optic nerve was crushed intraorbitally with fine curved forceps. If profuse bleeding occurred the animal was not used. The fish were then injected intraperitoneally with $3 \mathrm{H}$-thymidine (102 $\mathrm{Ci} / \mathrm{mmol}, 10 \mu \mathrm{Ci} / \mathrm{g}$ body weight) to label the mitotically active cells in the germinal zone at the edge of the retina (Johns, '77; Meyer, '78). The labeled cohort of cells served to mark the edges of both retinae (left and right) at the time of nerve crush. The fish were revived and returned to their aquaria. Months later, when they were killed, the annulus of radioactive cells in the experimental retina delimited the boundary between those ganglion cells present at the time of the crush which have regenerated their axon and the new ganglion cells added at the periphery subsequent to the crush which have a newly grown (not regenerated) axon.

\section{HRP labeling}

After 14-16 months, by which time the fish had grown to $46-85-\mathrm{mm}$ standard body length, they were anesthetized (as before), and the skull overlying the tectum was removed. Two small groups of fascicles, one central and the other peripheral (at the medial periphery of the dorsal hemitectum), were cut and labeled with HRP (Fig. 1). Both right (control) and left (experimental) sides were labeled. Details of the surgical procedure were as described previously (Stuermer and Easter, '84a,b; Bernhardt and Easter, '86).

Four days after the HRP application the fish were reanesthetized, both right and left eyes were removed, and the fish were then perfused with buffered glutaraldehyde. The retinae were whole-mounted (see Bernhardt and Easter, '86). The brains were embedded in gelatin/sucrose and 40 $\mu \mathrm{m}$ transverse sections were cut on a freezing microtome. To obtain sections of the optic pathway at an angle roughly perpendicular to the course of the axons, the brain was cut in a semihorizontal plane (see Bernhardt and Easter, '86). The sections and the whole-mounted retinae were processed for HRP by using diaminobenzidine (DAB) with cobalt intensification (Adams, '81) and then counterstained with methylene green. The retinae were sampled systematically at $400 \times$, and the outermost HRP-labeled cells in a group were connected on the drawings to define the boundary. The regions within the boundaries are stippled on the drawings.

We have found the DAB chromogen to be the most reliable in our hands, and since the fish were so special, representing more than a year's survival, we used DAB. The disadvantage of this chromagen is its nonspecific labeling, particularly of endothelial cells, erythrocytes, and the pia. The nonspecific labeling is pointed out in representative photomicrographs, but, for reasons of clarity, most of the data are presented as camera lucida drawings.

Areas were measured on these calibrated drawings with a digitizing pad (Zeiss MOP-3).

\section{Autoradiography}

The retinal whole mounts that had previously been processed for HRP were embedded in glycomethacrylate (Sorval Embedding Medium, Dupont) and sectioned tangential to the retinal surface at $3 \mu \mathrm{m}$. Slides with mounted sections were dipped in nuclear emulsion (N'TB-2, Kodak) and exposed at $4^{\circ} \mathrm{C}$ for $3-8$ weeks. The autoradiographs were developed in Kodak D-19 as previously described (Johns, '82). Because the embedded retinae were not completely flat, individual sections did not include the whole retinal area. The retinae were partly reconstructed from outline drawings of adjacent sections, and the radial distance from the annulus of $3 \mathrm{H}$-thymidine-labeled cells to the optic disk was determined in at least two retinal quadrants. A circle of corresponding radius marks the position of the radioactively labeled cells in the original drawing of the HRP. processed retinal whole mount. Because the reconstructions of the autoradiographs did not include the complete retinal margin in all four retinal quadrants, the measurements of radial distance are designated as approximate. We are confident that our reconstructions of the radioactive annuli are reliable even though only two radial measurements were made, since previous work has shown that the relative position of the optic disk remains stable during postlarval development (Raymond, '86). 
TABLE 1. Retina Data

\begin{tabular}{|c|c|c|c|c|c|}
\hline \multirow[b]{2}{*}{ Animal } & \multirow{2}{*}{$\begin{array}{l}\text { Body length } \\
\text { (mm) }\end{array}$} & \multicolumn{2}{|c|}{$\begin{array}{l}\text { Retinal area } \\
\qquad\left(\mathrm{mm}^{2}\right)\end{array}$} & \multicolumn{2}{|c|}{$\begin{array}{l}\text { Approx. \% radial } \\
\text { distance of } \\
\text { ratioactive } \\
\text { annulus } \\
\text { from optic disk }\end{array}$} \\
\hline & & Right & Left & Right & Left \\
\hline $6-13-1$ & 46 & 35.31 & 33.32 & 84 & 84 \\
\hline 6-19-2 & 53 & 36.63 & 35.70 & -1 & $-^{2}$ \\
\hline $6 \cdot 27 \cdot 1$ & 57 & 36.17 & 33.10 & 79 & $-^{2}$ \\
\hline $6-27-2$ & 52 & $29.97^{3}$ & $27.82^{3}$ & -1 & $-{ }^{2}$ \\
\hline $7-4-1$ & 68 & 48.95 & 47.73 & 82 & $-^{2}$ \\
\hline $7-25-1$ & 69 & 46.18 & 52.93 & 78 & $-^{2}$ \\
\hline $7-25-2$ & 71 & 51.44 & 56.85 & ${ }^{1}$ & $-^{2}$ \\
\hline $8-2-1$ & 82 & 55.18 & 50.82 & $-^{1}$ & $-^{2}$ \\
\hline
\end{tabular}

${ }^{1}$ No radioactive label detected.

${ }^{2}$ Not reconstructed.

${ }^{3}$ Retinal margins damaged, area probably underestimated

\section{RESULTS \\ Retinal growth}

All retinae had grown considerably between the time of nerve crush and the HRP application. Retinal areas in the eight experimental animals ranged from $27.82 \mathrm{~mm}^{2}$ to 56.85 $\mathrm{mm}^{2}$, with larger fish generally having larger retinae (Table 1). The average area of nine retinae from five small fish (30-33-mm body length) similar in size to the experimental fish at the time of nerve crush was $11.24 \mathrm{~mm}^{2}$ (range 9.62$13.55 \mathrm{~mm}^{2}$ ). Thus the experimental retinae had increased in area approximately threefold over the course of the experiment. The increase reflects both stretch of preexisting retina and addition of new retina from the marginal growth zone. These measurements are consistent with data based on sectioned material from normal animals (Raymond, '86).

In the retinae of four fish, 3H-thymidine-labeled cells were detected. They formed an annulus at $78-84 \%$ of the radial distance from the optic disc (Table 1, Fig. 2B). Thus, about $36 \%$ of the entire retina lay outside the ring. The amount of new retina that had been added proved sufficient to allow the selective labeling of new ganglion cells and their axons (see below).

The retinal growth rate was not affected by the nerve crush. Table 1 shows that the experimental (right) and the control (left) retina in each fish were of similar size. In one control retina the radial distance from the optic disc to the ring of radioactively labeled cells was also measured and found to be the same as in the corresponding experimental retina (Table 1, compare Fig. 2A,B). At a rate of 40-50 ganglion cells per day (Easter et al., '81), 17,000-24,000 new cells should have been added over the 14-16-month survival.

In four animals no radioactive label was detected. One of us has noted a similar loss of label over months of survival: the intensity of radioactive labeling was found to differ between the two retinae of the same animal-one removed shortly after an intraperitoneal injection of $3 \mathrm{H}$-thymidine, the other after a longer survival period (P.A. Raymond, unpublished results). Possible explanations are proton exchange or DNA repair. Another possibility is that some injections of the radioactive tracer were not successful Whatever the reasons for the four failures, the four successes gave consistent results, as Table 1 shows. We therefore assume that in the four unlabeled retinae, cells at radial distances greater than about $80 \%$ had been added after optic nerve regeneration.

\section{HRP labeling}

The data are presented in two parts: the locations of the HRP-labeled ganglion cells in retinal flat mounts and the locations of labeled axons in the cross sections of the optic tract. For both, the description of the normal pathway precedes that of the experimental (regenerated) pathway.

\section{Retinal origins of tectal fascicles}

Control retinae. On the dorsal tectum, the optic axons course in fascicles that diverge from the rostral tectal pole, steadily shrink as they lose axons, and disappear at the tectal equator (Fig. 1). We refer to those that disappear more rostrally as "central" fascicles and to those that disappear more caudally as "peripheral." Tectal fascicles normally contain axons of similar age, sharing a common radial distance from the optic disc (an $r$-group: Bernhardt and Easter, '86). Central fascicles contain older axons, originating from central retina, and successively more peripheral fascicles are successively younger. The youngest axons, from the retinal margin, course along the tectal periphery (for details see Stuermer and Easter, '84b). This organization is illustrated after the application of HRP to two dorsal fascicles on a control tectum. Labeled ganglion cells were restricted to the ventral half of the corresponding retina (Figs. 2A, 3A, 4G) and occupied two partial annuli. Based on previous studies (Stuermer and Easter, '84b; Bernhardt and Easter, '86) we concluded that the more central annulus was labeled through the fascicle on central tectum and that the more peripheral annulus was labeled from the peripheral tectal fascicle. The central annular segment lay entirely within the ring of radioactive cells, and the peripheral segment was completely outside (Fig. 2A).

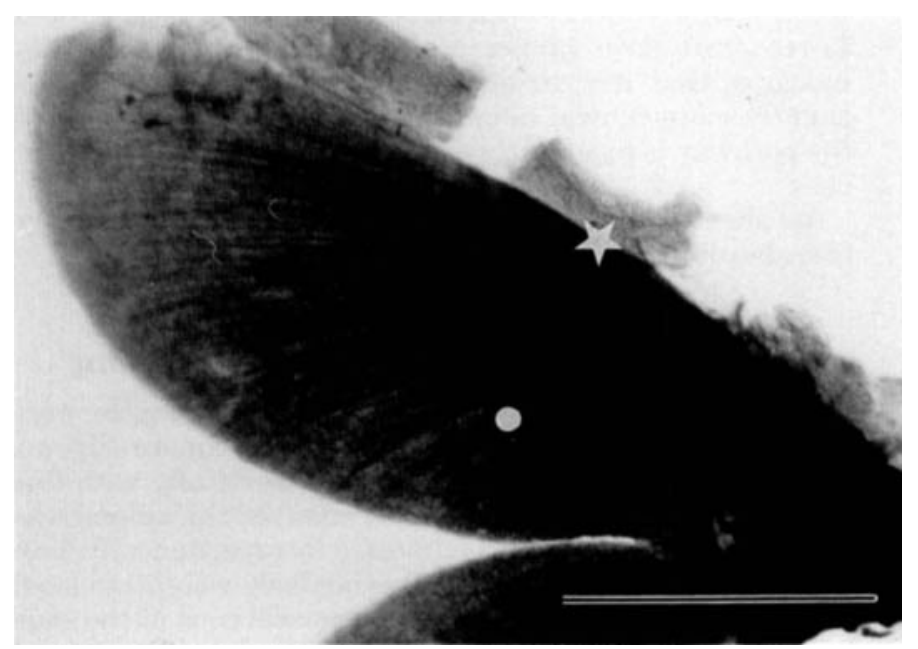

Fig. 1. The approximate locations of the central (dot) and the peripheral (star) HRP application sites are indicated in this micrograph illustrating the dorsal half of a whole-mounted control tectum. A relaxing cut (curved edge) was made along the tectal equator to allow for flattening of the tectal hemisphere. The axons constituting the tectal fascicles have been visualized after application of HRP to the cut intraorbital nerve. Rostral is to the right, caudal to the left, medial (dorsal) up. Axons course in fascicles that diverge from the rostral tectal pole and disappear near the tectal equator. In the text, fascicles that disappear more rostrally are referred to as "central" fascicles and those that that disappear more caudally as more "peripheral." Calibration bar, $1.0 \mathrm{~mm}$. 

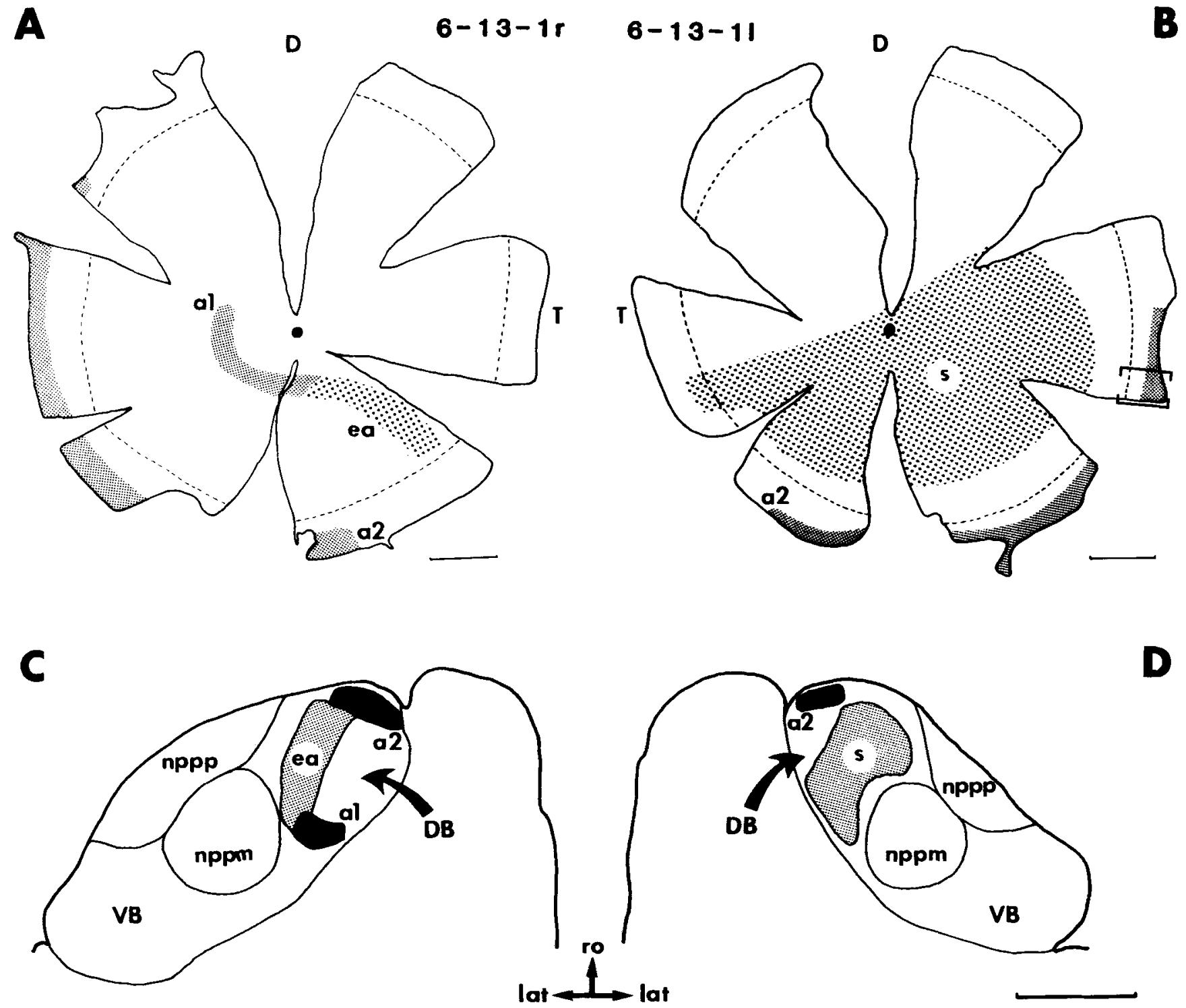

D

Fig. 2. Retrograde labeling through intact and regenerated optic pathways. A,B: Left control (A) and right experimental (B) retinae of animal 6 . 13-1. C,D: Sections through the brachia of the corresponding optic tracts at the level of nppm. Camera lucida drawings. Micrographs of sections through the dorsal brachia of this animal are illustrated in Figure 6A,B. A,B: Dense stippling indicates the annular component of HRP labeling; loose stippling indicates extraannular labeling (handle of the sickle) in A and scattered cells in B. Dotted line marks position of radioactive cells. Boxed region in B is illustrated by micrographs in Figure 5. C,D: The optic tracts are illus-

In six out of eight control retinae an additional group of labeled ganglion cells was observed after applications to rostrocentral tectum. It extended linearly from the temporal edge of the central partial annulus toward the temporal retinal margin (Figs. 2A, 4G). This complex sickleshaped pattern has been previously analyzed in detail (Easter and Stuermer, '84). In brief, the handle of the sickle ("ea" on Fig. 2A) represents the contribution of labeling terminal arborizations and extrafascicular axons; the blade, or annulus portion, represents fascicular labeling. As in the simpler annular pattern described in the preceding paragraph, the blade of the sickle lay entirely inside the ring of trated by a low-power view of both the dorsal and ventrai brachia in sections cut at a semihorizontal plane through the diencephalon (see Bernhardt and Easter, '86, for details). Stippling indicates labeled axons from indicated retinal regions. a1, central partial annulus; a2, peripheral partial annulus; ea, extraannular segment; s, scattered cells; D, dorsal; $T$, temporal; DB, dorsal brachium; VB, ventral brachium; nppm, nucleus pretectalis superficialis pars magnocellularis; nppp, nucleus pretectalis superficialis pars parvicellularis; ro, rostrodorsal; lat, lateral. Calibration bar, $1.0 \mathrm{~mm}$ in $\mathrm{A}, \mathrm{B}$; $0.5 \mathrm{~mm}$ in $\mathrm{C}, \mathrm{D}$.

radioactive cells. This sickle-shaped pattern was never seen after labeling at the extreme tectal periphery (Easter and Stuermer, '84).

We conclude that the central and peripheral application sites were suitable to probe the experimental pathways followed by regenerated and newly added axons, respectively.

Experimental retinae. In the central region of the experimental retinae the pattern was very different from that in controls. In seven of eight cases ganglion cell somata labeled through a central tectal fascicle were scattered throughout central retina and were not clustered in an arc 

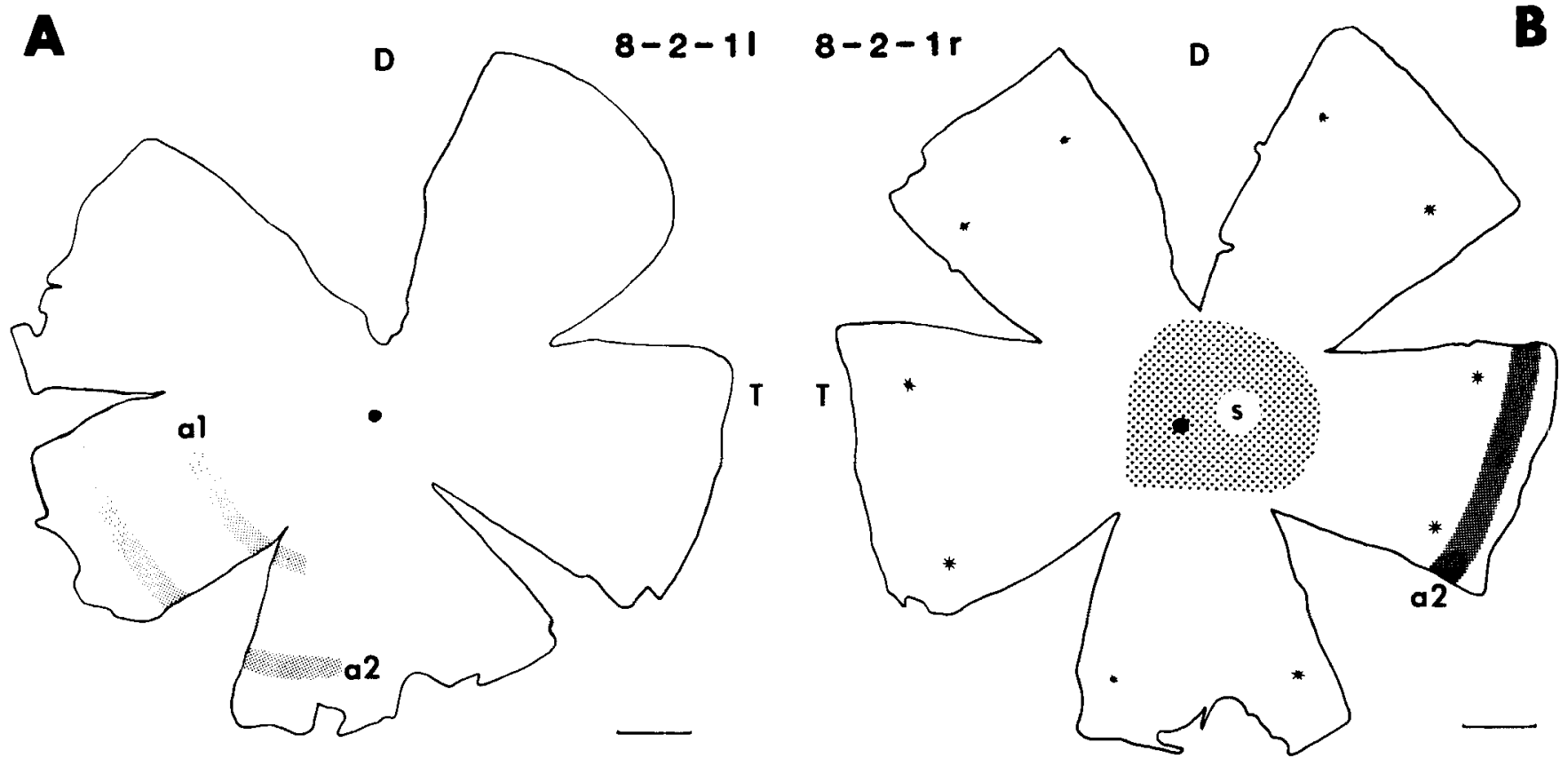

C
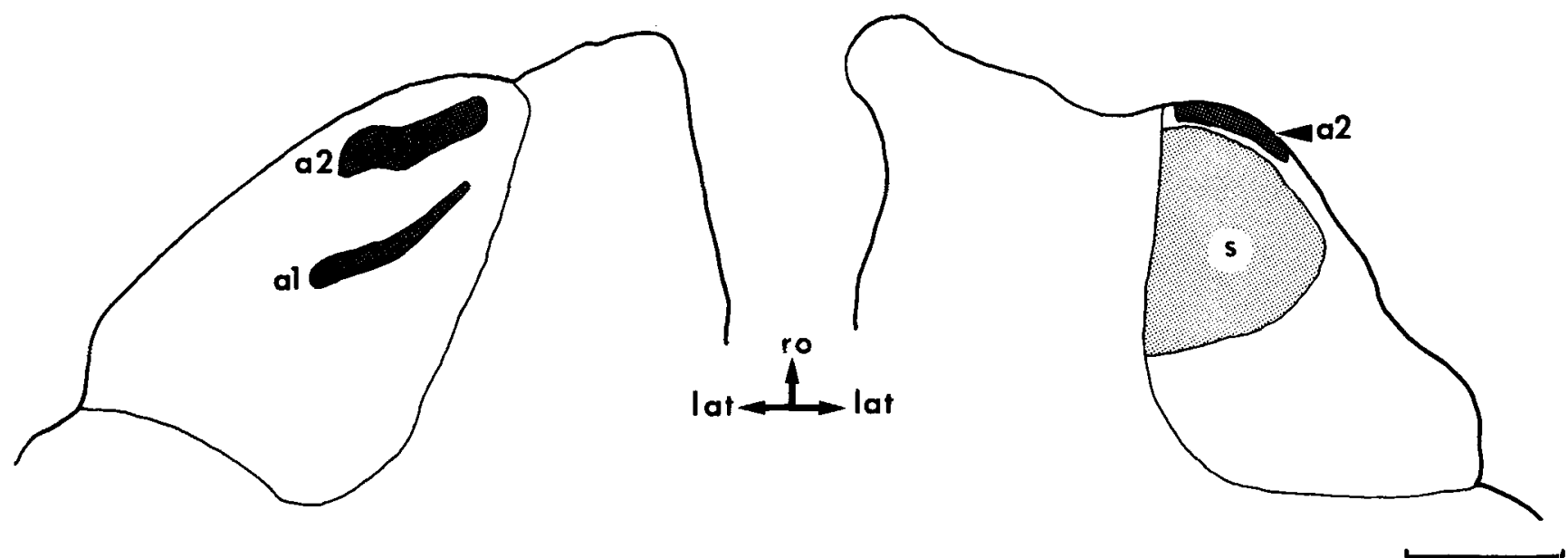

Fig. 3. Retrograde labeling through intact and regenerated pathways. Left control (A) and right experimental (B) retinae of animal 8-2-1. Sections through the corresponding optic tracts near the brachial split (C,D). Camera lucida drawings. Micrographs of these tracts are illustrated in Figure 6C,D. Conventions are the same as in Figure 1. In this animal no radioac-

tive label was detected. Asterisks in B mark the approximate extent of the precrush retina ( $80 \%$ retinal radius), an estimate based on four other fish (see Table 1). Abbreviations as in Figure 2. Calibration bar, $1.0 \mathrm{~mm}$ in A,B $0.5 \mathrm{~mm}$ in $\mathrm{C}, \mathrm{D}$.

(Figs. 2B, 3B, 4A-E). In the one exceptional case, a distinct partial annulus of clustered labeled cells was embedded in the more scattered ones (Fig, 4F). We suggest that this exceptional case had an incomplete crush (see below). In the remaining seven cases the absence of a central annulus confirms that the nerve had been effectively crushed (Cook, '83; Stuermer and Easter, '84a).

In seven of eight cases, the HRP-labeled cells were confined by the ring of radioactive cells and had therefore been born before the nerve was crushed. In the single exception, the HRP-labeled cells intersected the ring in ventrotemporal retina, shown in Figure 2B. This was the only case in

which new cells lay in the same group as old ones. There are two possible explanations for the backfilling of newly added ganglion cells from the central tectal application site: 1) some of the new axons might have grown directly into central tectum, alongside their regenerated predecessors, or, 2) the new axons did not reach central tectum directly when they first grew out but entered it only later, as part of the events associated with shifting terminals. As a result of the discordant growth patterns of the retina and tectum, retinal terminals (which at all times project retinotopically) shift caudally on the tectum. Previous work in goldfish (Easter and Stuermer, '84; Stuermer and Easter, '84b; Ray- 

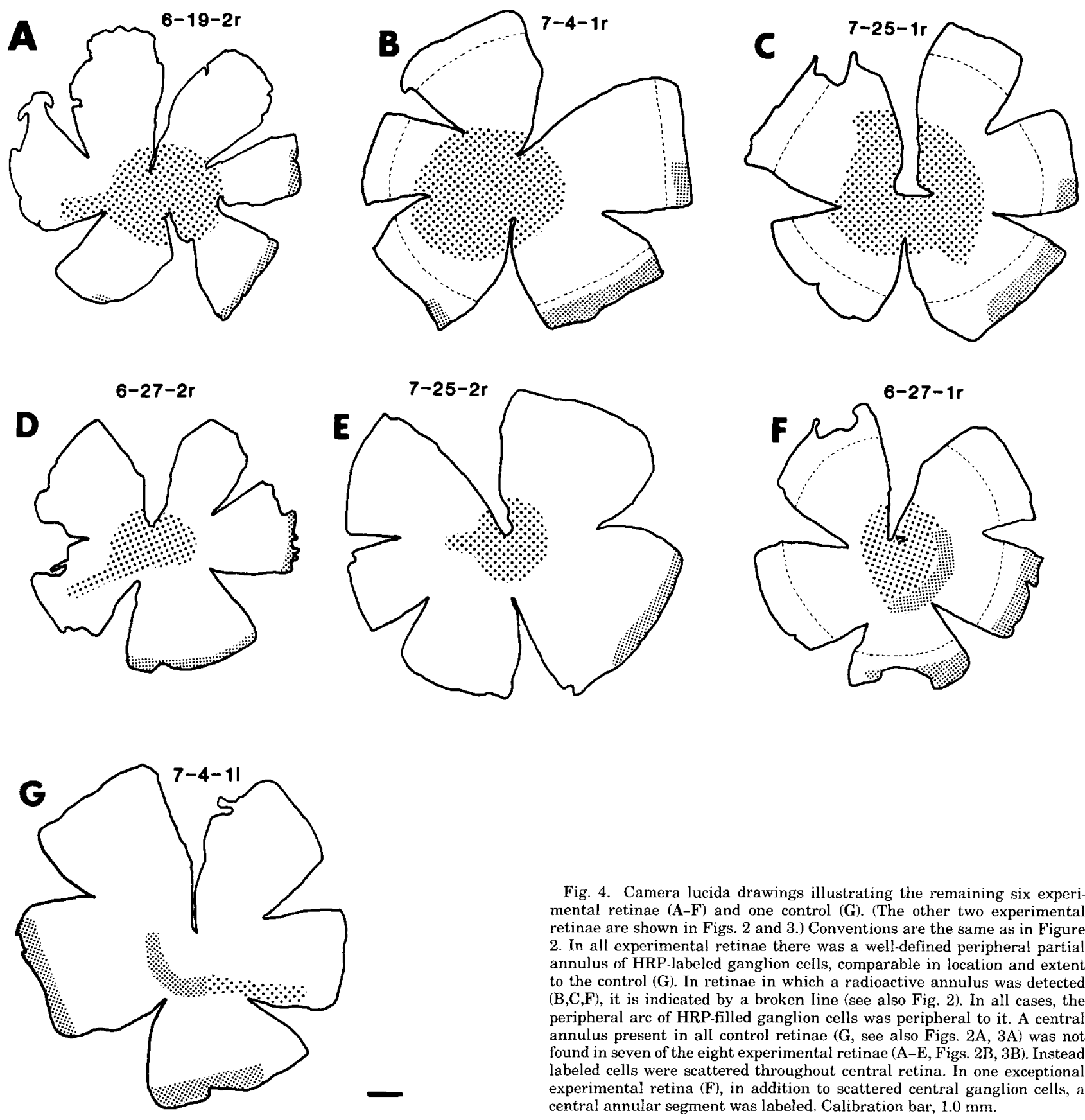

Fig. 4. Camera lucida drawings illustrating the remaining six experimental retinae (A-F) and one control (G). (The other two experimental retinae are shown in Figs. 2 and 3.) Conventions are the same as in Figure 2 . In all experimental retinae there was a well-defined peripheral partial annulus of HRP-labeled ganglion cells, comparable in location and extent to the control $(G)$. In retinae in which a radioactive annulus was detected (B,C,F), it is indicated by a broken line (see also Fig. 2). In all cases, the peripheral arc of HRP-filled ganglion cells was peripheral to it. A central annulus present in all control retinae ( $G$, see also Figs. $2 \mathrm{~A}, 3 \mathrm{~A})$ was not found in seven of the eight experimental retinae (A-E, Figs. 2B, 3B). Instead labeled cells were scattered throughout central retina. In one exceptional experimental retina (F), in addition to scattered central ganglion cells, a central annular segment was labeled, Calibration bar, $1.0 \mathrm{~mm}$.

mond, '86) has shown that the displacement is largest for fibers from temporal retina which move caudally at a rate of about $5 \mu \mathrm{m} /$ day (Raymond, ' 86 ). These observations lead us to favor the second alternative, since the location of this small group of cells, in ventrotemporal retina, is consistent with that interpretation.

In all experimental retinae, a labeled peripheral partial annulus was found outside the ring of radioactive cells (Figs. 2-5), exactly where it would be expected if the new ganglion cells sent their axons through the normal path way along the tectal edge. The likelihood that they did so is strengthened by the analysis of the pathway, the subject of the next section.

\section{Organization of the optic tract}

Control tract. The topography of the regenerated and the nonregenerated axons was examined in cross sections of the optic tract of the same animals. Two distinct bands of HRP-labeled axons, one deep and the other more superficial, were always found in control tracts (Figs. 2C, 3C, $6 \mathrm{~A}, \mathrm{C})$. These axons were traced to the central and peripheral tectal application sites, confirming earlier work (Bernhardt and Easter, '86). In those cases in which the labeled zone in central retina was sickle-shaped (reflecting extrafascicular and terminal labeling in addition to fascicular labeling, as described above), a group of labeled axons in the tract ("ea" in Fig. 2C) extended along the central to 


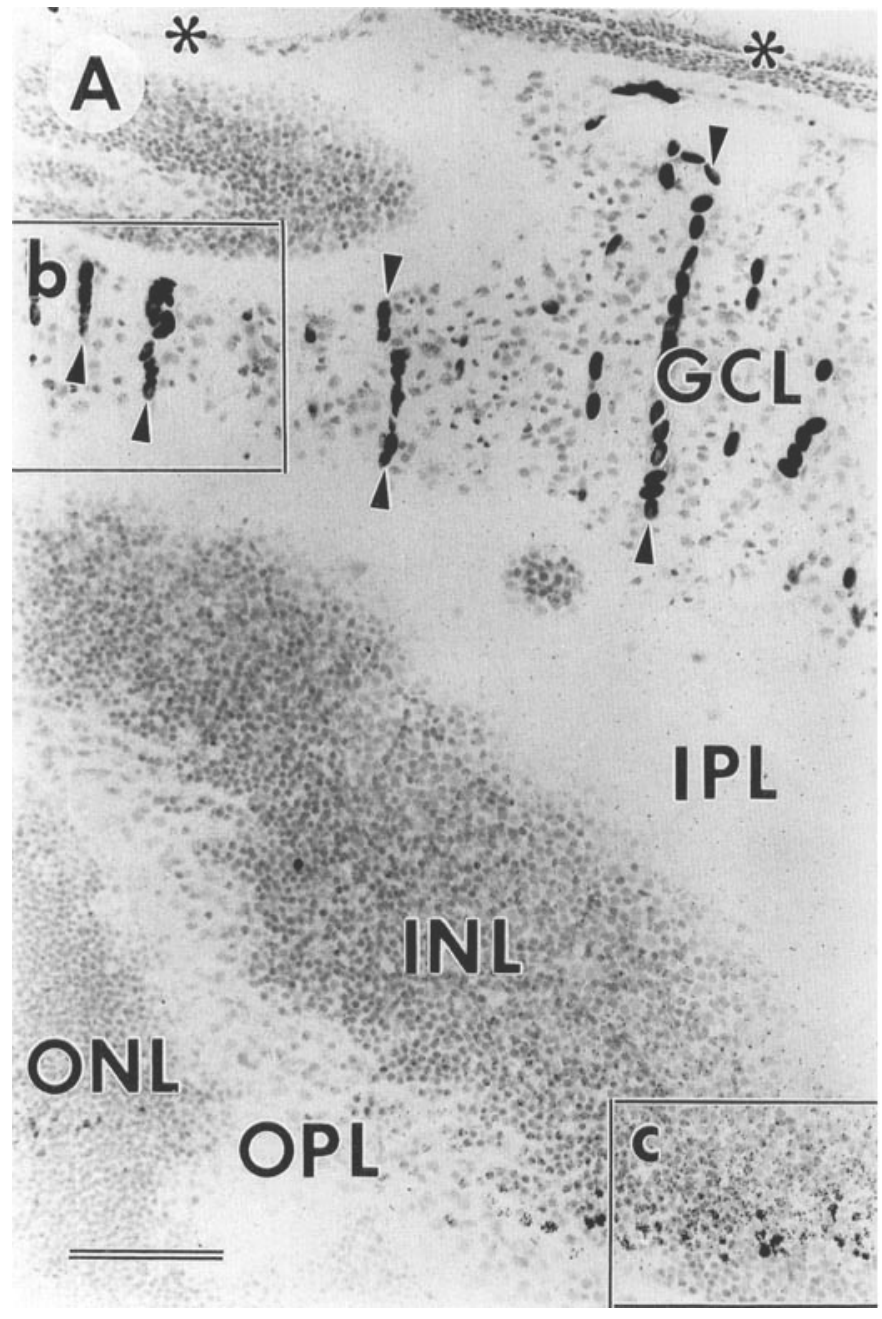

Fig. 5. Dual labeling of the retina. An orienting overview (A) and two high-power micrographs illustrating HRP-labeled ganglion cells of a peripheral retinal annulus (B) and 3H-thymidine-labeled cells (C). A: A tangential section through an experimental retina (6-13-1r) treated for autoradiography and counterstained. The location of this micrograph is indicated in a camera lucida drawing of the same retina (Fig. 2B). Because the retina was not embedded perfectly flat the section grazes different retinal layers. The boxed region (b), containing HRP-labeled ganglion cells that are difficult to discern at low magnification, is shown at higher magnification in B. Radio-
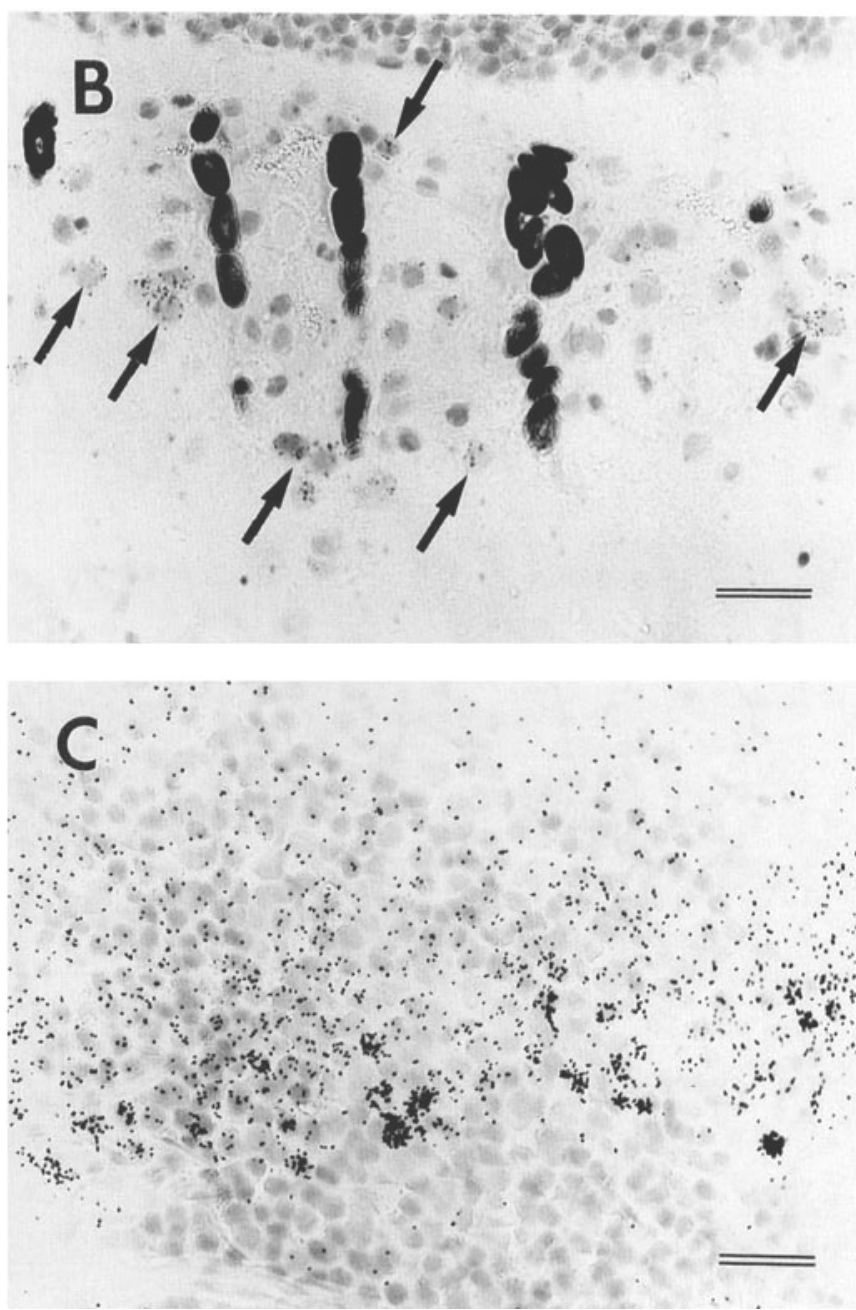

actively labeled cells in the boxed region (c) are shown at higher magnification in $\mathrm{C}$. Asterisks indicate the retinal margin; arrowheads indicate erythrocyte-filled blood vessels in the ganglion cell layer. B: A high-power micrograph, illustrating HRP-labeled ganglion cells (arrows). C: High-power micrograph showing $3 \mathrm{H}$-thymidine labeled cells in the inner nuclear layer. GCL, ganglion cell layer; INL, inner nuclear layer; IPL, inner plexiform layer; ONL, outer nuclear layer; OPL, outer plexiform layer. Calibration bars, $100 \mu \mathrm{m}(\mathrm{A}), 25 \mu \mathrm{m}$ (B,C). superficial axis in a region previously demonstrated to contain temporal axons (Figs. 2C, 6A) (Bunt, '82; Springer and Mednick, '85; Bernhardt and Easter, '86).

Experimental tract. In the experimental pathways the labeling pattern was different. There was no dense central band of stained axons in seven of the eight fish. Instead, the labeled axons were dispersed over most of the dorsal arm of the tract (" $\mathrm{s}$ " in Figs. 2D, 3D; Fig. 6B, D). (In only one case was there evidence of a central band of labeled axons, and this was in the same fish whose retina contained a central partial annulus. This reinforces our belief that the nerve had been incompletely crushed.) The scattered axons were traced to the central tectal application site and therefore originated from central retina; they must have been regenerates. All experimental tracts also contained a dense band of labeled axons near the pia ("a2" in Figs. 2D, $3 \mathrm{D}, 6 \mathrm{~B}, \mathrm{D})$. These axons were traced to the peripheral labeled tectal fascicle, and they originated from a peripheral retinal annulus, outside the ring of radioactive cells. Therefore, they must have been added after the nerve wass crushed. The pathway followed by these axons was indistin. guishable from that of normal fibers derived from ganglion cells of equivalent positions on the normal side. Thus, in the brachium of the experimental tract the newly added axons, originating from nasoventral retina, were clustered far from the nucleus pretectalis superficialis pars magnocellularis (nppm), like their counterparts in the control pathway. This indicates that in addition to restoring order along the $r$-axis they had also established normal order along the $\theta$-axis of the pathway (see companion paper; Bern- 

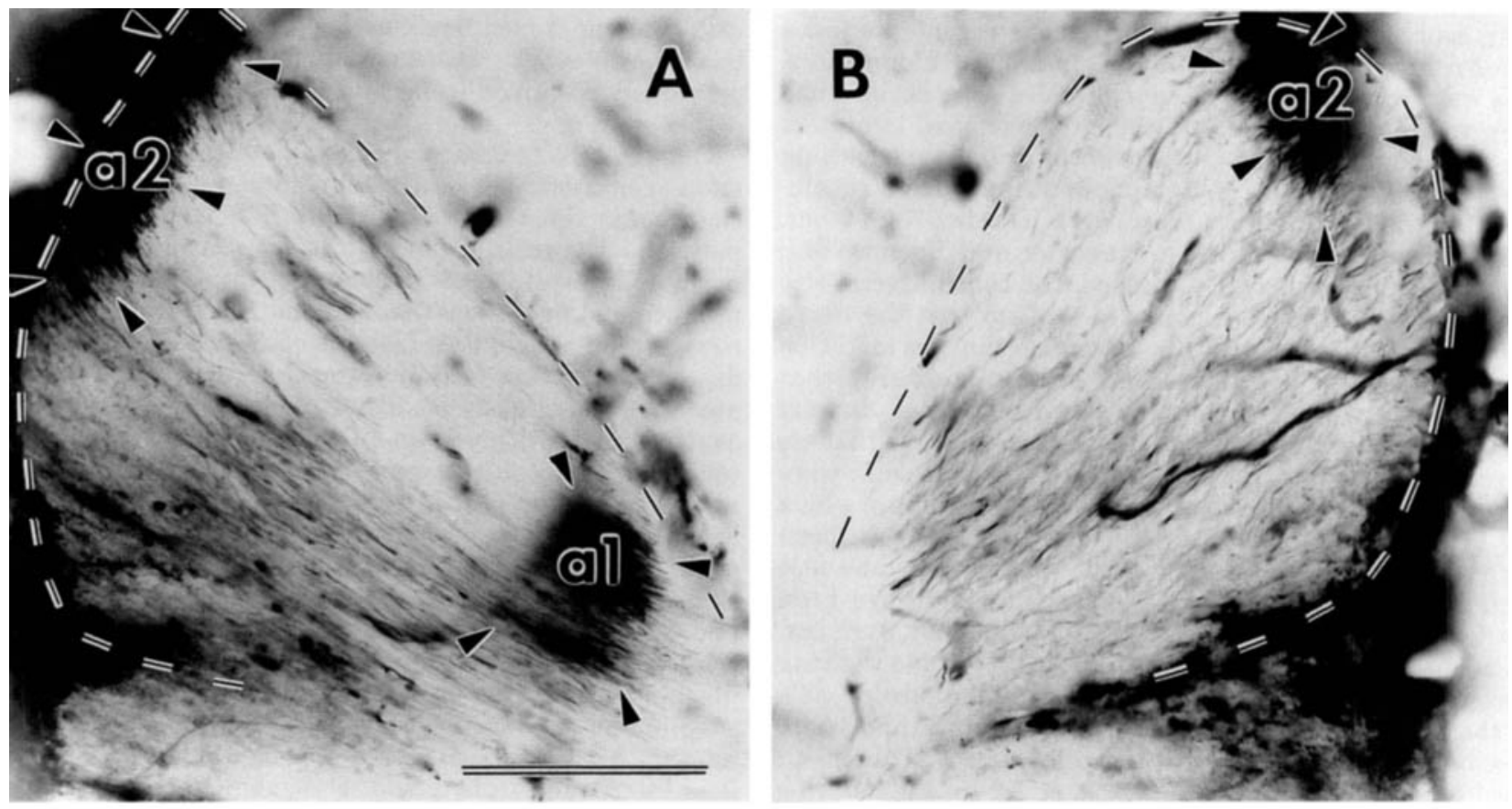

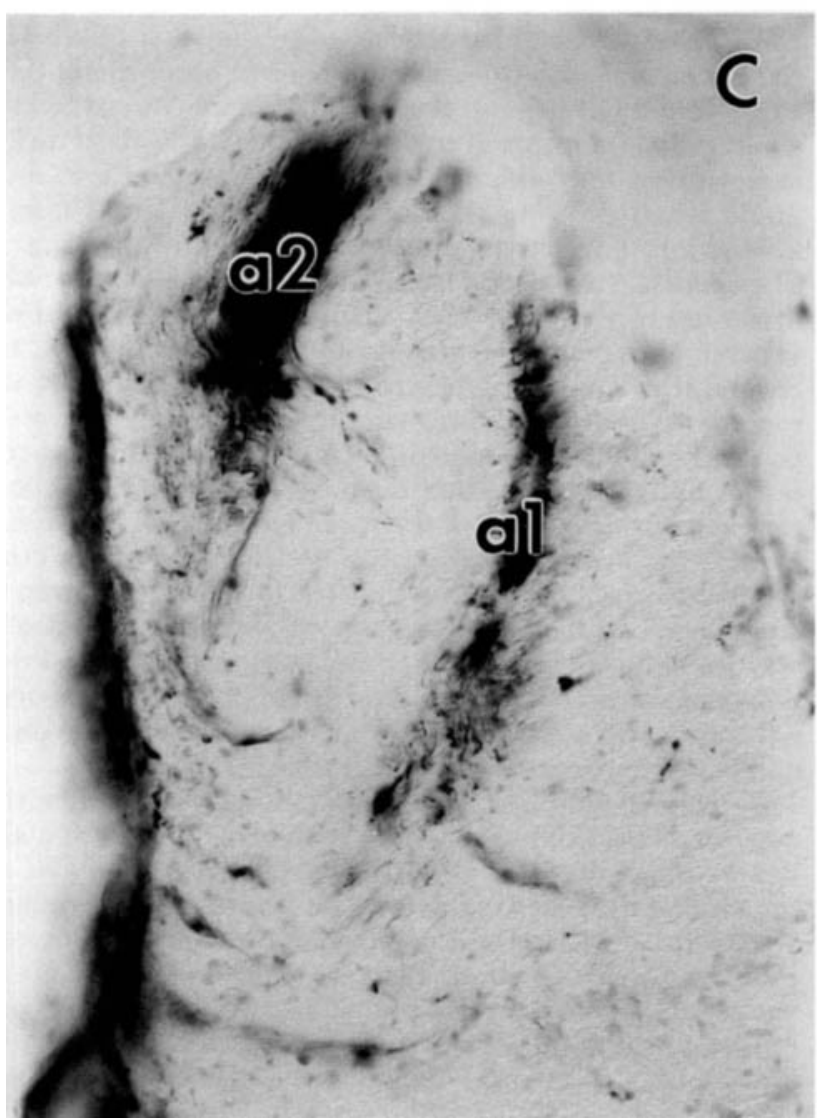

Fig. 6. Two pairs of micrographs illustrating the distribution of labeled axons in control $(A, C)$ and experimental $(B, D)$ tracts. Sections are cut in a semihorizontal plane through the diencephalon, perpendicular to the pathway. Rostrodorsal is up, medial toward the center. Calibration bar, $100 \mu \mathrm{m}$.

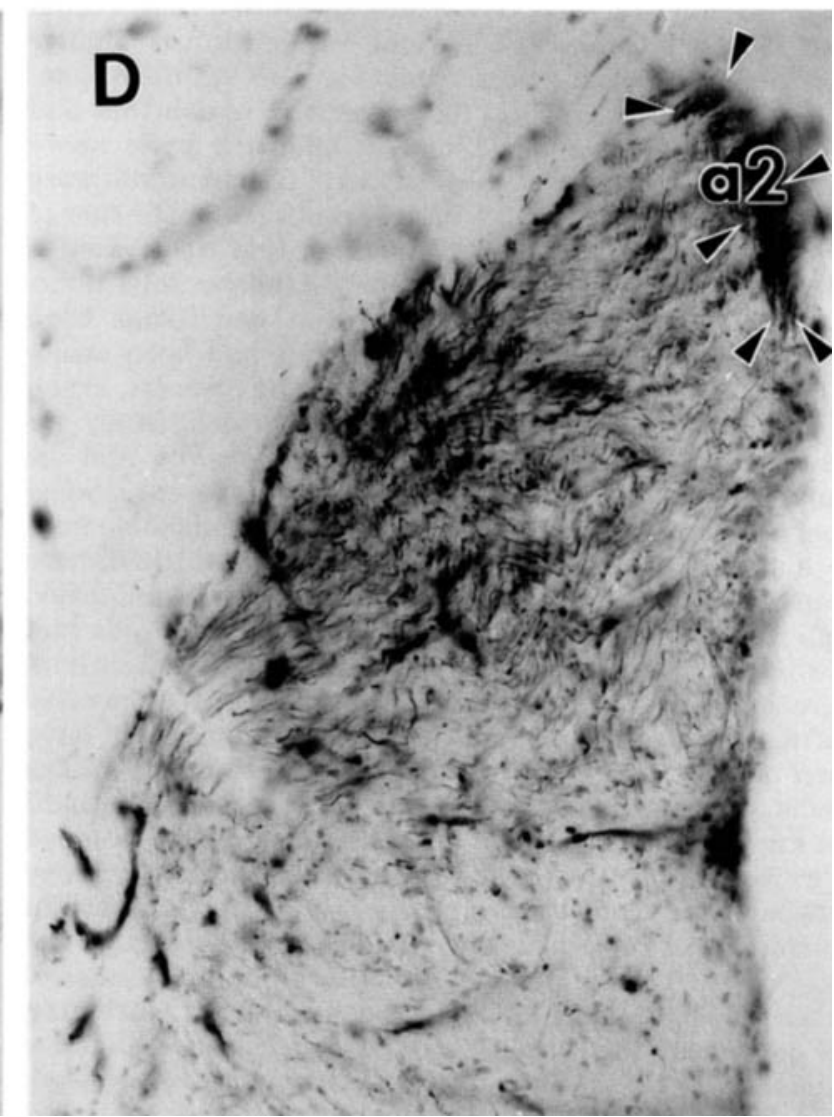

A,B: Details of the dorsal brachia shown as camera lucida drawings in Figure 2C,D. Abbreviations as in Figure 2. C,D: Details of the optic tracts shown as camera lucida drawings in Figure 3C,D. Abbreviations as in Figure 2. 
hardt and Easter, '86, '88).

We conclude 1) that the crushed axons regenerated in a pattern in which much of the original order along the $r$ axis was lost, and 2) that the axons added after nerve crush grew in along the normal trajectory (the subpial lamina in the tract and the outermost edge of the brachium enclosing the tectum.) There can be little doubt about the first conclusion, as it is supported by other work (Horder, '74; Meyer, '80; Dawnay, '81; Cook, '83; Stuermer and Easter, '84a; Bernhardt and Easter, ' 88 ). Indeed, the central tectal site was labeled in this experiment to confirm that the nerve crush had been effective. The second conclusion might be doubted, however. Have we ruled out the possibility that some of the new ganglion cells sent their axons directly into the deep tract and central tectum? We believe that we have, since the two labeled groups of retinal cells were always separated by a gap of unlabeled cells, many of which lay outside the radioactive ring, and had therefore been born after nerve crush (Figs. 2-4). If some of these had sent their axons centrally, they would presumably have been labeled by the central HRP application, but they were not. With one exception, the only labeled cells outside the ring were those in a position corresponding to the labeled cells on the normal side, and we have provided an explanation, based on earlier work, of the exceptional case. Thus, both conclusions appear justified.

\section{DISCUSSION}

Our observation, that new axons added to a regenerated optic pathway establish a normal $r$-order, differs slightly from another recent report. Stuermer ('86) backfilled ganglion cells from peripheral tectal fascicles of fish that had survived for 2,4 , and 12 months following optic nerve section and reported that the peripheral retinal annuli were less well defined than in an intact projection. In the case of the animals that survived 12 months, this was taken to indicate either that axons from new ganglion cells intermixed with regenerated axons or that new axons were influenced by the abnormal routes that had been established in the regenerated pathway. Our results argue against the second alternative. In the present study we waited longer after nerve crush before labeling and we found that the peripheral retinal annuli that were labeled from peripheral tectal fascicles were indistinguishable from normal ones. In our fish the new retina constituted more than $30 \%$ of the whole-enough to provide an unlabeled buffer zone between the peripheral HRP-labeled cells and the $3 \mathrm{H}$-thymidine-labeled cells. Most of Stuermer's results were obtained from shorter survivals ( 2 and 4 months) during which time relatively little new retina would have been added. Stuermer did not mark the boundary of the retina at the time of optic nerve section and therefore could not know which of the HRP-labeled somata had been added after regeneration. We suggest that the minor discrepancy between Stuermer's study and ours reflects a difference in the amount of new retina added after the transection of the optic nerve. The simplest explanation is that the crushed axons regenerated across the entire tectal surface including the dorsomedial margin, where the next generation of new axons also grew. If only a little new retina had been added, then application of HRP to a peripheral tectal fascicle would label a mixed population of both new axons and regenerates; since the latter originate from sites scattered throughout the retina, the wider-spread retinal origins, Stuermer's result, would be expected. Our results were obtained after addition of a substantial amount of new retina. They indjcate that the mixed fascicles had been displaced from the tectal periphery by axons of new ganglion cells, a pattern previously described in normal fish (Stuermer and Easter, '84b).

This study was designed to examine the contribution of axon-axon tracking in the establishment of the fiber topography, and the $r$-axis in particular, of the goldfish optic pathway. Our results show that new axons added in a normal developmental sequence to a regenerated optic pathway did not follow the aberrant routes taken by their regenerated neighbors. Instead of coursing through the depths of the cross section of the tract, where the regenerated axons of slightly smaller r-value had grown, the new axons coursed with one another in the optic tract and tectum and their positions were similar to those of correspond. ing axons on the control side. These results are therefore incompatible with the hypothesis that growing axons depend for guidance primarily on their predecessors from slightly more central retinal regions (Fawcett, '85; Taylor and Gaze, '86). They are consistent with the proposal that r-order reflects a general adhesion between new axons (Bernhardt and Easter, '86) and a permissive role of the subpial region of the pathway (Rusoff, ' 84 ; Silver and Rutishauser, '84; Easter, '87; see also Walsh and Guillery, '85). It is interesting to note that the subpial zone is not only preferred by growth cones of axons but by migrating cells as well (Hausmann et al., '87; Sotelo and Alvarado-Mallart, '87).

We have not examined closely the question of whether the new axons also assumed the normal order along the $\theta$ axis (We did not use intraretinal HRP applications to label small groups of axons of common $\theta$.), but three observations suggest that they did, at least to some degree. First, retrograde labelings from the dorsal peripheral tectal fascicle always labeled a partial annulus in the ventral hemiretina. Therefore the axons had made the appropriate choice at the brachium of the optic tract, where fibers from dorsal and ventral hemiretinae segregate (Attardi and Sperry, '63). Second, the angular subtense of the partial annulus was roughly normal, suggesting that the axons from ventrotemporal ganglion cells had exited the brachium first, as they do normally (Stuermer and Easter, '84b). Third, the labeled new axons, originating in the nasal quadrant of the ventral hemiretina, occupied appropriate positions within the crosssectioned dorsal brachium-that is, they were clustered far from nppm. In the preceding paper (Bernhardt and Easter, '88) we have concluded that regenerated axons followed nonaxonal cues to reestablish a crude version of the original $\theta$-order.We suggest that the new ones could also do so, and our data are consistent with that idea.

We believe that our results exclude the possibility that new axons selectively associate with other axons from similar retinal addresses. But we do not wish to leave the impression that existing axons play no role in the guidance of growth cones. Indeed, our recent work has emphasized that the growth cones of new optic axons in goldfish preferentially elongate on their immediate predecessors in both de novo outgrowth (Easter et al., '84) and regeneration (Easter, '87). Similarly, Grant and Ma ('86) have demon strated that scrambled optic axons in Xenopus will regenerate on any of several preexisting sets of axons, including peripheral ones. But we have no evidence that growth cones recognize, or grow upon, axons from neighboring retinal regions in preference to axons from more distant sites. 
Thus, preceding axons probably provide nonspecific guidance. In the metaphor of automobiles, the road bed is provided by the axons, but the direction signs are found elsewhere.

Finally, we are not suggesting that axons entirely lack an identity, nor are we denying the phenomenon of axoaxonal recognition, for which convincing evidence exists both in vitro (Bray et al., '80; Kapfhammer et al., '86; Kapfhammer and Raper, '87) and in vivo (Raper et al., '84; Kuwada, '86). But in those cases, growth cones encountered axons of various origins, such as retina and sympathetic ganglion, and selectively associated with some axons and avoided different ones. In the case of the visual pathway, it has been suggested that retinal axons might be capable of recognizing the sectoral origins of other axons and then preferentially associating with those of the same sector. Bonhoeffer and Huf ('85) have demonstrated that some chick retinal axons can do this, in vitro, and it is possible that some of the sectoral order among the new axons in this study was brought about by such selectivity. But the very tight $r$ order was restored in the new portions of the pathway despite the severely degraded r-order in the regenerated pathway. We feel confident that this aspect of order must arise without any contribution from specific axoaxonal guidance.

\section{ACKNOWLEDGMENTS}

This work was supported by research grants EY-00168 and EY-04318 to S.S.E. and P.A.R., respectively, and by a grant from the Janggen-Poehn Stiftung to R.B. P.A.R. is a fellow of the Alfred P. Sloan Foundation.

We thank Dr. Steven Scherer for his early suggestions about this approach, Dr. Kathryn Tosney for useful comments on the manuscript, Mr. David Bay for photography, Ms. Patricia Rivlin for expert technical assistance, and Ms. Linda Freeman for typing the paper.

\section{LITERATURE CITED}

Adams, J.C. (1981) Heavy metal intensification of DAB-based HRP reaction product. J. Histochem. Cytochem. 26:775.

Attardi, D.G., and R.W. Sperry (1963) Preferential selection of central path ways by regenerating optic fibers. Exp. Neurol. 7:46-64.

Bernhardt, R., and S.S. Easter (1986) The map of retinal position onto the cross section of the optic pathway of goldfish. J. Comp. Neurol. 254:493510.

Bernhardt, R., and S.S. Easter (1988) Regenerated optic fibers in goldfish reestablish a crude sectoral order in the visual pathway. J. Comp. Neurol. 277:403-419.

Bernhardt, R., S.S. Easter, P. Raymond, and P. Rivlin (1986) Axons added to the optic pathway subsequent to its regeneration reestablish the normal fiber topography lost during regeneration. Soc. Neurosci. Abstr. 12:1211.

Bodick, N., and C. Levinthal (1980) Growing optic nerve fibers follow neigh bors during embryogenesis. Proc. Natl. Acad. Sci. USA 77:4374-4378.

Bonhoeffer, F., and J. Huf (1985) Position-dependent properties of retinal axons and their growth cones. Nature 315:409-410.

Bray, D., P. Wood, and R.P. Bunge (1980) Selective fasciculation of nerve fibers in culture. Exp. Cell Res. 130:241-250.

Bunt, S.M. (1982) Retinotopic and temporal organization of the optic nerve and tracts in adult goldfish. J. Comp. Neurol. 206:209-226.

Cook, J.E. (1983) Tectal paths of regenerated optic axons in the goldfish: Evidence from retrograde labeling with horseradish peroxidase. Exp. Brain Res. 51:433-442.

Dawnay, N.A.H. (1981) Fibre ordering within regenerated optic pathways of goldfish. J. Physiol. (Lond.) 317:76P-77P.

Easter, S.S. (1987) Retinal axons and the basal lamina. In M.J.R. Wolff, J Sievers, and M. Berry (eds): Mesenchymal-Epithelial Interactions in Neural Development. New York: Springer-Verlag, pp. 385-396.
Easter, S.S., and C.A.O. Stuermer (1984) An evaluation of the hypothesis of shifting terminals in goldfish optic tectum. J. Neurosei. 4:1052-1063.

Easter, S.S., A.C. Rusoff, and P.E. Kish (1981) The growth and organization of the optic nerve and tract in juvenile and adult goldfish. J. Neurosci. 1:793-811.

Easter S.S., B. Bratton, and S.S. Scherer (1984) Growth-related order of the retinal fiber layer in goldfish. J. Neurosci. 4:2173-2190.

Fawcett, J.W. (1985) Factors guiding regenerating retinotectal fibers in the frog Xenopus laevis. J. Embryol. Exp. Morphol. 90:233-250.

Fraley, S.M., and S.C. Sharma (1986) Retinal topography in the optic tract of adult goldfish. Neuroscience. 19:1363-1380.

Grant, P., and P.M. Ma (1986) Optic fibers follow aberrant pathways from rotated eyes in Xenopus laevis. J. Comp. Neurol. 250:364-376.

Hausmann, B., D. Hartmann, and J. Sievers (1987) Secondary neuroepithe lial stem cells of the cerebellum and the dentate gyrus are attached to the basal lamina during their migration and proliferation. In J.R. Wolff, J. Sievers, and M. Berry (eds): Mesenchymal-Epithelial Interactions in Neural Development. New York: Springer-Verlag, pp. 279-291.

Horder, T.J. (1974) Changes of fibre pathways in the goldfish optic tract following regeneration. Brain Res. 72:41-52.

Johns, P.R. (1977) Growth of the adult goldfish eye. III. Source of new retinal cells. J. Comp. Neurol. 176:343-358.

Johns, P.R. (1982) Formation of photoreceptors in larval and adult goldfish. J. Neurosci. 2:178-198.

Kapfhammer, J.P., B.E. Grunewald, and J.A. Raper (1986) The selective inhibition of growth cone extension by specific neurites in culture. J. Neurosci. 6:2527-2534.

Kapfhammer, J.P., and J.A. Raper (1987) Interactions between growth cones and neurites growing from different neural tissues in culture. J. Neurosci. 7:1595-1600

Kuwada, J.Y. (1986) Cell recognition by neuronal growth cones in a simple vertebrate embryo. Science 233:740-746.

Meyer, R.L. (1978) Evidence from thymidine labeling for continuing growth of retina and tectum in juvenile goldfish. Exp. Neurol. 59:99-111.

Meyer, R.L. (1980) Mapping the normal and regenerating retinotectal pro jection of goldfish with autoradiographic methods. J. Comp. Neurol. 189:273-289.

Raper, J.A., M.J. Bastiani, and C.S. Goodman (1984) Pathfinding by neuronal growth cones in grasshopper embryos: IV. The effects of ablating the $A$ and $P$ axons upon the behavior of the $G$ growth cones. J. Neurosci. 4:2329-2345.

Raymond, P.A. (1986) Movement of retinal terminals in goldfish optic tectum predicted by analysis of neuronal proliferation. J. Neurosci. 6:24792488.

Rusoff, A.C. (1984) The paths of axons in the visual system of perciform fish and implications of these paths for order governing axonal growth. J. Neurosci. 4:1414-1428.

Scholes, J.H. (1979) Nerve fibre topography in the retinal projection to the tectum. Nature 278:620-624.

Silver, J., and U. Rútishauser (1984) Guidance of optic axons in vivo by a preformed adhesive pathway on neuro-epithelial endfeet. Dev. Biol 106:485-499.

Sotelo, C., and R.M. Alvarado-Mallart (1987) Embryonic and adult neurons interact to allow Purkinje cell replacement in mutant cerebellum. Nature 327:421-423.

Springer, A.D., and A.S. Mednick (1985) Topography of the goldfish optic tracts: Implications for the chronological clustering model. J. Comp Neurol. 239:108-116.

Springer, A., and B. Mednick (1986) Retinotopic and chronotopic organization of retinal ganglion cell axons throughout the optic nerve. J. Comp. Neurol. 247:221-232.

Stuermer, C.A.O. (1986) Pathways of regenerated retinotectal axons in goldfish. 1. Optic nerve, tract and tectal fascicle layer. J. Embryol. Exp Morphol. 93:1-28.

Stuermer, C.A.O., and S.S. Easter (1984a) A comparison of the normal and regenerated retinotectal pathways of goldfish. J. Comp. Neurol. 223:5776

Stuermer, C.A.O., and S.S. Easter (1984b) Rules of order in the retinotectal fascicles of goldfish. J. Neurosci. 4:1045-1051.

Taylor, J.S.H., and R.M. Gaze (1986) The effects of the fibre environment on paths taken by regenerating optic nerve fibres in Xenopus. J. Embryol. Exp. Morphol. 89:383-401.

Walsh, C., and R.W. Guillery (1985) Age-related fiber order in the optic tract of the ferret. J. Neurosci. 5:3061-3069. 